\section{Unusual clinical course in a child with cystic fibrosis treated with fat emulsion}

Cystic fibrosis is recognized as a disease presenting with a wide spectrum of manifestations. Lung, pancreatic exocrine, sweat gland, and gut dysfunctions are commonly found, usually in combination. Although symptomatic treatment has greatly improved the prognosis, the disease is usually recognized as progressive, albeit sometimes at a slow pace.

This paper presents the early clinical course of one child with an unusual improvement, which may or may not be related to a novel form of treatment.

\section{Case report}

A girl was the first child born at term to healthy young parents, after a pregnancy complicated by toxaemia in the last few weeks. She weighed $2840 \mathrm{~g}$ at birth and appeared healthy, but 24 hours later she had not passed meconium and her abdomen was distended. $X$-ray of the abdomen showed gaseous distension of the small bowel. A Gastrografin enema and Gastrografin meal showed obstruction in the distal small bowel. Operation revealed meconium plugging of the distal ileum, and a Koop ileostomy was performed. Biopsy of the distal ileum showed normal innervation and structure, apart from eosinophilic concretions in the depths of some glandular lumens.

Her postoperative recovery was uneventful, but stool tryptic activity was 'absent' (gelatin digestion test) and a sweat test conducted at day 9 showed $\mathrm{Na} 76 \mathrm{mEq} / \mathrm{l}$. and chloride $94 \mathrm{mEq} / \mathrm{l}$. in $65 \mathrm{mg}$ of sweat. Chest $x$-ray was normal. A repeat sweat test showed a sodium concentration of $104 \mathrm{mEq} / \mathrm{l}$. at a sweat rate of $5 \cdot 2 \mathrm{~g} / \mathrm{m}^{2}$ per $\min$.

At this stage the diagnosis of cystic fibrosis was made, and a pancreatic extract (Viokase) and supplementary salt were given. Additionally, intravenous infusions of $20 \%$ soya oil emulsion (Intralipid) $5 \mathrm{ml} / \mathrm{kg}$ over 2 hours were given every 3-6 weeks.

Progress. At 5 months of age the child developed a spreading staphylococcal infection around the ileostomy site. This was treated with antibiotics and the ileostomy was excised. Apart from this incident, no antibiotics have been given as no clinical or radiological lung disease has developed. The child is now 19 months old and weight gain has progressed from the 3 rd centile to the 50 th centile.
Special investigations. Assays of stool tryptic and chymotryptic activity (Haverback et al., 1963) were carried out at 5 months of age, 3 days before and 4 days after an infusion of Intralipid. Viokase was stopped 4 days before the infusion was given. The enzyme levels were low and did not appear to respond to the infusion, but at 8 months of age normal activity of both enzymes appeared. Viokase was stopped permanently at that time and neither steatorrhoea nor disturbance of normal bowel habits occurred. Weight gain remained normal. Stool enzyme activity has remained in the normal range to date with a little decline since the infusions have been given 6-weekly (Fig. 1).

Fractional sweat tests in which sweat sodium was related to the rate of sweating (Schwarz and Thaysen, 1956) were performed immediately before the infusions of Intralipid. Before the initiation of treatment, sweat sodium concentrations were high, but declined to normal (or near normal) range. A change from 3-weekly to 6-weekly infusions were associated with a recurrence of raised sodium concentration (Fig. 2).

Individual fatty acid determinations (Morrison and Smith, 1964) in serum have been carried out only since the age of 11 months. These remained in the normal range until the infusions were given less frequently when the level of linoleic and arachidonic acid declined to a subnormal range, as judged by our laboratory.

\section{Discussion}

There seems little doubt that this child has cystic fibrosis. Adequate weight gain and apparently normal lung development in early life are somewhat unusual, but have been documented in many other cases previously. Though pancreatic achylia may not occur in $10 \%$ of cases, an apparent recovery of pancreatic function after previous achylia has not been documented.

A spontaneous decline in sweat sodium concentration has not been previously reported. Depression of the levels of essential fatty acids in cystic fibrosis has previously been found (Kuo, Huang, and Basset, 1962), but raising these concentrations into the normal range by parenteral administration has not been tried in the past.

It is tempting to suggest that the treatment may have influenced the course of the disease, but this is by no means proven.

It is possible (though not shown here) that defective absorption of essential fatty acids occurs in children with cystic fibrosis. Correction of the results of this hypothetical defect might correct some 


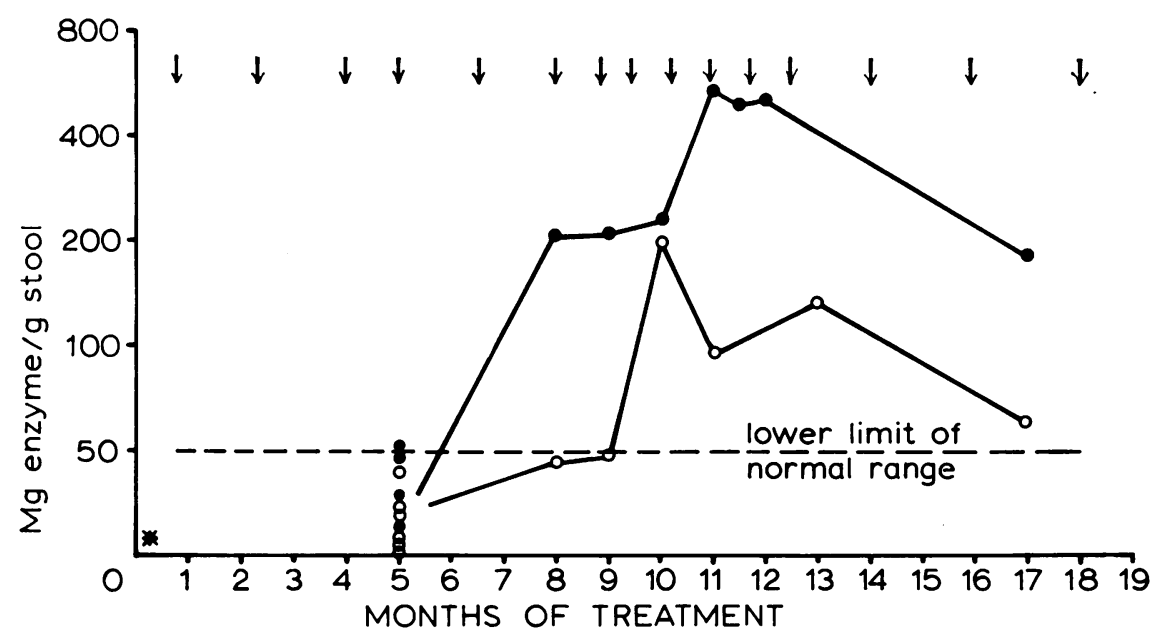

FIG. 1.-Stool tryptic $\bullet$ and chymotryptic $\bigcirc$ activity plotted against the age of the child and infusions of intralipid $\downarrow$. $\star$ Reported tryptic activity by gelatin digestion.

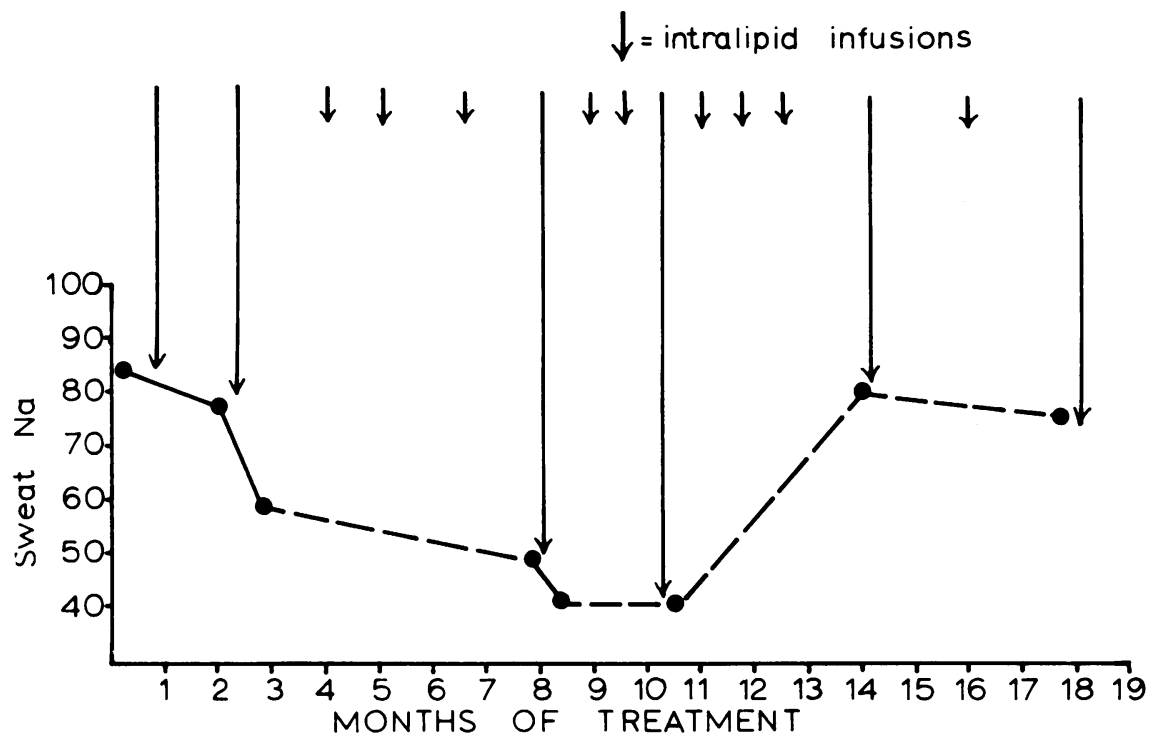

FIG. 2.-Sweat sodium concentration $\left(2.5 \mathrm{~g} / \mathrm{m}^{2}\right.$ per min sweat rate) during treatment, plotted against the age of the child, and infusions of intralipid $\downarrow$.

of the clinical manifestations of the disease. A defect in placental transfer of essential fatty acids would have to be considered to account for meconium ileus.

The role of essential fatty acids in the biosynthesis of prostaglandins is well documented, as is the effect of prostaglandins on ion transfer (Cuthbert, 1973).
Disordered prostaglandin biosynthesis could conceivably account for many of the ductular and ionic transfer disorders in the disease. Essential fatty acid deficiency has been experimentally induced in young children (Hansen et al., 1958) and the clinical picture does not particularly resemble cystic fibrosis, though it is of interest to note that at least one of the 
16 children so depleted for 3 months developed staphylococcal pneumonia. Essential fatty acid deficiency in the developing chick produces failure to thrive and mesobronchitis with many similarities to cystic fibrosis (Hopkins, Witter, and Nesheim, 1963), and the genital changes in developing male rabbits rendered fatty acid-deficient (Ahluwalia, Pincus, and Holman, 1967) are suggestive of the changes found in males with cystic fibrosis.

While it is obviously impossible to know whether the case of cystic fibrosis described shows a hitherto undescribed spontaneous variation in the course of the disease, or whether the novel treatment may have caused the improvement, the authors consider that the variation in itself and the rationale of treatment are worth bringing to the attention of other doctors and research workers.

\section{Summary}

A child diagnosed as having cystic fibrosis by customary criteria has been given regular parenteral soya oil emulsion from near birth. Sweat tests have improved, pancreatic achylia was relieved, and the child at present remains entirely well. Correction of the essential fatty acid deficiency found in cystic fibrosis may prevent some of the manifestations of the disease.

We wish to acknowledge the financial support of the Medical Research Council of New Zealand.

\section{REFBRENCES}

Ahluwalia, B., Pincus, G., and Holman, R. T. (1967). Essential fatty acid deficiency and its effects upon reproductive organs of male rabbits. Fournal of Nutrition, 92, 205.

Cuthbert, M. F. (1973). Review in The Prostaglandins. Ed. by M. F. Cuthbert. Heinemann, London.

Hansen, A. E., Haggard, M. E., Boelsche, A. N., Adam, D. J. D., and Wiese, H. F. (1958). Essential fatty acids in infant nutrition. fournal of Nutrition, 66, 565.

Haverback, B. J., Dyce, B. J., Gutentag, P. J., and Montgomery, D. W. (1963). Measurement of trypsin and chymotrypsin in stool. Gastroenterology, 44, 588.

Hopkins, D. T., Witter, R. L., and Nesheim, M. C. (1963). A respiratory disease syndrome in chickens fed essential fatty acid deficient diets. Proceedings of the Society for Experimental Biology and Medicine, 114, 82.

Kuo, P. T., Huang, N. N., and Basset, D. R. (1962). The fatty acid composition of the serum chylomicrons and adipose tissue of children with cystic fibrosis of the pancreas. Fournal of Pediatrics, 60, 394.

Morrison, W. R., and Smith, L. M. (1964). Preparation of fatty acid methyl esters and dimethylacetals from lipids with boron fluoride-methanol. Fournal of Lipid Research, 5, 600.

Schwarz, I. L., and Thaysen, J. H. (1956). Excretion of sodium and potassium in human sweat. fournal of Clinical Investigation, 35, 114.

R. B. Elliott* and P. G. Robinson

Department of Paediatrics, School of Medicine, University of Auckland, N.Z.

*Correspondence to Professor R. B. Elliott.

\section{Early life of the 'battered child'}

Investigations in recent years into the nature of the battered child syndrome (Kempe et al., 1962) and the problems that are connected with it have resulted in a much clearer understanding of the processes leading to child abuse (Skinner and Castle, 1969; Cameron, 1970). An area that was felt to merit further study in this respect was the importance of the pregnancy and early life of children who were later abused. It has been suggested that factors such as poor attention to antenatal care, prematurity, low birthweight, and separation from the mother in the neonatal period may be significant (Courte, 1969; Klein and Stern, 1971). The aim of this preliminary study was to find factors which might be of value in the prediction and thereby the prevention of child abuse.

\section{Methods}

In the London Borough of Lambeth cases of 'battering' are reported to the Directorate of Health Observation Handicap Unit which follows them up until the child's fifth birthday when they are transferred to the School Health Service. Accordingly, it was possible to look at all the 28 cases recorded up to December 1972. All the available records were reviewed and in all but four instances we saw the homes and met the parents on follow-up visits.

Information was obtained from the Observation Handicap Unit files, the hospital maternity and neonatal records, the Child Health Clinic records, and by discussion with the general practitioners and health visitors involved.

A control group for comparison of perinatal factors, matched for sex of child and month of birth, was selected from King's College Hospital birth register by means of a table of random numbers. This was felt to be a comparable group as all the abused children had been delivered in hospitals, mainly in South London.

\section{Results}

The cases studied here were drawn from a population of 24300 children under the age of 5 years. Of the 28 abused, 23 were under 2 years and 27 under 3 years of age (see Fig.) giving an incidence of roughly 2 per 1000 in children 3 years and under. The true incidence will be considerably greater as many cases are either unrecognized or unreported (Jackson, 1972).

Only 10 of the children were girls. In 14 instances the child abused was the youngest child in the family, reflecting the age distribution and possibly a certain vulnerability of the last born. 7 were 'only' children and 3 were the eldest child. In 